\title{
TROPICALISMO E CINEMA NA CONSTRUÇÃO DE UMA IDEN- TIDADE CULTURAL NACIONAL
}

TROPICALISM AND CINEMA IN THE CONSTRUCTION OF A NATIONAL CULTURAL IDENTITY

TROPICALISMO Y CINEMA EN LA CONSTRUCIÓN DE UNA IDENTIDAD CULTURAL NACIONAL

Walace Rodrigues

Doutorando em Humanidades e Professor Assistente da Universidade Federal do Tocantins (UFT) walace@uft.edu.br

RESUMO: Este escrito busca trabalhar com a identificação nacional na época do movimento tropicalista. Para tal, utiliza-se duas obras de cinema no intuito de melhor ilustrar os mecanismos discursivos críticos usados pelos tropicalistas. Estas obras cinematográficas são "Macunaíma", de Joaquim Pedro de Andrade, de 1969, e "Bye Bye Brasil" de Carlos (Cacá) Diegues, de 1979. As obras se utilizam claramente de uma estética tropicalista para abordarem a nação brasileira e uma busca de identidade nacional. A utilização de obras de arte cinematográficas, ambas com caráter tão nitidamente brasileiro, pode revelar-nos alguns importantes aspectos identitários próprios da sociedade nacional.

PALAVRAS-CHAVE: Tropicalismo. Identidade Nacional. Cultura. Sociedade. Cinema.

ABSTRACT: This paper aims to work with national identification during the times of tropicalist movement. To do so we use two artworks from cinema trying to better illustrate the critical discursive mechanisms used by the tropicalists. These two cinematographic works are "Macunaíma", by Joaquim Pedro de Andrade, from 1969, and "Bye Bye Brasil", by Carlos (Cacá) Diegues, from 1979. The works clearly make use of the tropicalist aesthetics to understand the Brazilian nation and to search for an nation identity. The utilization of cinematographic artworks, clearly brazilians, can reveal us some aspects important identity of the national society.

KEYWORDS: Tropicalism. National identity. Culture. Society. Cinema.

RESUMEN: Este escrito intenta trabajar con la identificación nacional en la época del movimiento tropicalista. Para tal, utilizase de dos obras del cine brasileño para mejor ilustrar los mecanismos discursivos críticos usados por los tropicalistas. Estas obras cinematográficas son "Macunaíma", de Joaquim Pedro de Andrade, de 1969, y "Bye Bye Brasil" de Carlos (Cacá) Diegues, de 1979. Las obras se utilizan claramente de una estética tropicalista para abordaren la nación brasileña y una busca de identidad nacional. La utilización de obras de arte cinematográficas, con motivos tan claramente brasileños, poden revelarnos algunos importantes aspectos propios de la identidad y de la sociedad nacional.

PALABRAS CLAVE: Tropicalismo. Identidad Nacional. Cultura. Sociedad. Cine.

$\overline{\text { Artigo recebido em maio de } 2014}$

Aprovado em julho de 2014 


\section{1 | INTRODUÇÃO}

Este escrito busca focar em minha área de formação, as artes visuais, e tentar desenvolver uma relação produtiva e frutífera de considerações intelectuais baseada em referências bibliográficas e em obras de arte cinematográfica.

A relação entre os mecanismos artísticos do Movimento Tropicalista (conhecido também como Tropicália ou Tropicalismo, acontecido no final da década de 1960 e começo da década de 1970), da busca pela compreensão de "uma" identidade cultural nacional se coloca como o foco deste artigo, no qual os procedimentos estéticos adotados pelos tropicalistas se podem notar nas duas obras fílmicas escolhidas para serem analisadas.

Assim sendo, este artigo tenta investigar, através de duas criações cinematográficas do mesmo período do Movimento Tropicalista, os procedimentos deste movimento que nasce em $1968 \mathrm{e}$ segue pela década de 1970. Os dois filmes que servem de base às articulações intelectuais deste escrito são o filme "Macunaíma" de Joaquim Pedro de Andrade, de 1969, e "Bye Bye Brasil" de Carlos (Cacá) Diegues, de 1979. Um se localiza no começo do Movimento Tropicalista e outro no seu período final.

As análises dos filmes, neste artigo, serão de natureza informativa e exemplificativa, destacando os aspectos mais relevantes destas obras cinematográficas para uma discussão acerca da busca de "uma" identidade cultural nacional. Isto contribuirá para a discussão da proposta deste trabalho, no sentido de fundamentar esteticamente os pontos onde o tropicalismo se coloca como uma "doutrina" de desvendamento dos vários brasis, existentes na época dos filmes trabalhados.

\section{2 | A ESTÉTICA TROPICALISTA E SEUS DESDOBRAMENTOS NO CINEMA}

Para falar da cultura brasileira no século XX, é necessário mencionar dois movimentos importantes que revolucionavam a vida intelectual e artística deste país: o Antropofagismo Modernista e o Tropicalismo. Um nos começos do século e outro nas décadas de 1960 e 1970.

Se o Antropofagismo Modernista tentou tomar todas as influências culturais na vida brasileira da década de 1920 e degluti-las, buscando uma síntese que fosse esteticamente produtiva, o tropicalismo, por sua vez, com forte influencia dos antropofágicos modernistas, desenvolveu uma leitura re-interpretativa da sociedade brasileira e de seus inúmeros símbolos, costumes e afetos.

Ambos os movimentos buscaram compreender os vários pontos da vida cultural brasileira e utilizá-los enquanto materiais estéticos específicos, para a construção crítica de um estilo de arte "tropical", que fosse produtiva tanto do ponto de vista artístico como político. No entanto, o Tropicalismo se torna um movimento extremamente mais crítico da sociedade e do momento político brasileiro de sua época do que a idealização ainda romântica dos modernistas.

Também, tomo aqui como "identidade cultural nacional" a identificação com uma nação que é definida através de aspectos culturais, acreditando que a identificação pessoal com um determinado país se dá por meio das teias de significações (para lembrar Clifford Geertz) na qual um sujeito está ligado culturalmente. Utilizo uma passagem de Geertz $(2008$, p. 36) para confirmar nossa ligação íntima com nossa cultura:

[...] nós somos animais incompletos e inacabados que nos completamos eacabamos através da cultura - não através da cultura em geral, mas através de formas altamente particulares de cultura: dobuana ejavanesa, Hopi e italiana, de classe alta e classe baixa, acadêmica ecomercial. A grande capacidade de aprendizagem do homem, sua plasticidade, tem sido observada muitas vezes, mas o que é ainda mais crítico é sua extrema dependência de uma espécie 
de aprendizado: atingir conceitos, a apreensão e aplicação de sistemas específicos de significado simbólico.

A escolha por produtos do cinema nacional para trabalhar com "uma" identidade cultural nacional se dá pela força desta forma de arte enquanto representação da "verdade". Explico-me mais claramente: assim como a fotografia, o cinema nos leva a crer no que vemos sem que nos questionemos muito sobre um entendimento de que cada criação fílmica é uma construção humana (uma representação) que carrega significações várias. Vale lembrar que essas significações não são fixas. Acredito, assim como os teóricos dos Estudos Culturais Ingleses, que a ideia central para entender como construímos significação, enquanto cultura, é via representação.

Ainda, tomo aqui o cinema como uma forma de linguagem, e linguagem como qualquer coisa que mostra significados (ex: discurso, escrita, dança, gestos, imagens, etc.). Assim, o cinema enquanto linguagem externaliza os significados que nós damos ao mundo que nos rodeia e serve de material para este artigo, enquanto forma de representação da cultura nacional. Principalmente os dois filmes selecionados, já que estes têm caráter profundamente questionador sobre os vários brasis que nos constitui.

Vale informar, também, que o grupo tropicalista tinha como seus maiores representantes Caetano Veloso, Gilberto Gil, Tom Zé, Torquato Neto, os Mutantes e Gal Costa. Provavelmente, o tropicalista-intelectual mais importante para o movimento tenha sido Caetano Veloso. Caetano Veloso (Caetano Emanuel Viana Teles Veloso), nascido a 7 de Agosto de 1942, em Santo Amaro, Estado da Bahia, é cantor, compositor, escritor e um dos mais importantes pensadores brasileiros.

Suas criações têm ajudado a compreender mais profundamente a cultura brasileira. Sua contribuição inestimável, durante o Tropicalismo, fez de Caetano um personagem legendário na história da música brasileira. Uma de suas criações, a canção chamada "Tropicália", de Caetano Veloso, de 1968, pode ser considerada como uma forma de representação da identidade brasileira nos fins da década de 1960.

O movimento tropicalista se dá durante a ditadura militar no Brasil. A ditadura militar foi instaurada em 1964 e oficialmente terminada em 1985, sendo que o período mais autoritário aconteceu depois da criação do Ato Institucional número 5 (Al-5), de 13 de dezembro de 1968, que suspendia todos os direitos civis dos cidadãos. A partir deste ato, a vida cultural brasileira mudaria de rumo com a forte influência da censura pública sobre todos os campos culturais. Utilizo uma passagem de Randal Johnson (2004, p. 131, tradução nossa), que clarifica este período da história brasileira, dando especial atenção à literatura:

O golpe de estado militar de 1964 que deu inicio a vinte e um anos de regime ditatorial obviamente teve um grande impacto na literatura e cultura brasileiras. Numerosos trabalhos de ficção têm explorado o impacto e ramificações do autoritarismo, assim como o movimento de resistência que se ergueu contra este regime militar.

Durante esse período histórico, marcado pela ditadura e pelo $\mathrm{Al}-5$, surgiu o movimento Tropicalista. Inovando pelas roupas, cabelos, músicas, influências, instrumentos musicais e referências culturais, sociais e políticas. O "[...] tropicalismo capta a vertiginosa espiral descendente do impasse institucional que levaria ao AI-5." (WISNIK, 1979, p. 16) e a canção "Tropicália" pode ser vista como uma boa representante deste período histórico.

Também, apesar do movimento tropicalista ter seu centro na área musical, ele não deixava de se conectar e relacionar-se com o cinema, o teatro, as artes plásticas e a televisão. Por ser um movimento que ocorre durante os famosos e populares festivais da canção, ele se beneficia, também, da difusão televisiva para concretizar-se e popularizar-se. 
Ainda, se os tropicalistas não criaram um manifesto para difundir as ideias de seu movimento, como os modernistas o haviam feito (aliás, os modernistas criaram vários manifestos e revistas), a música "Tropicália" dava a linha de pensamento e de mecanismos estéticos utilizados pelo movimento tropicalista. Nela observamos o uso de uma mistura, aparentemente desconexa, de várias representações "tipicamente" brasileiras, como a construção de Brasília, a figura de Carmen Miranda, o carnaval, as terras férteis e verdejantes, a figura da mulata, as águas azuis, os coqueiros, entre outros. Coloco, aqui, uma passagem de Celso Favaretto $(1979$, p. 43) sobre como funcionava o intrincado mecanismo de composição da letra de "Tropicália":

\begin{abstract}
Através do pastiche, parodiam-se os mitos assimilados a um certo sentimentalismo nacionalista (incorporação de dilemas à José de Alencar, Catulo da Paixão Cearense, Olavo Bilac); expõem-se as mazelas do subdesenvolvimento; as posturas de esquerda e de direita; a ideia de uma fatalidade histórica, em forma de um "destino nacional"; o mito de que tudo se resolve em festa (o carnaval oficial, o futebol, a televisão), que preenche o cotidiano e alivia a tensão. $O$ efeito crítico não provém da simples justaposição do arcaico e do moderno, que poderiam conviver numa desordem "mantida", mas do estilhaçamento do painel que vai se montando; indica-se constantemente que o carnaval é suspeito e que a carnavalização da música é outra coisa, enquanto representa a representação.
\end{abstract}

Assim sendo, o mecanismo tropicalista é o mecanismo de inventariar representações e ir tencionando-as, relacionando-as, estilhaçando-as. A partir do momento, em que se vê tantas representações tão diferentes umas das outras e tão abrangentes, nota-se que elas não se ligam coerentemente e que o acúmulo se destina à explosão. Parece que há uma assemblage ${ }^{1}$ proposital de referências culturais com o intuito de nos fazer pensar. Utilizo-me, aqui, de uma passagem de Homi Bhabha (2003, p. 439, tradução nossa) sobre a importância da ambivalência e complexidade na construção da arte atual, o que se relaciona perfeitamente com os mecanismos estéticos dos tropicalistas:

O valor da arte não está em seu alcance transcendente, mas na sua capacidade de tradução; na possibilidade de mover-se entre meios, materiais e gêneros, cada vez marcando e remarcando as fronteiras materiais da diferença; articulando 'lugares' onde a questão da 'especificidade' é ambivalente e complexamente construída.

Lilia Moritz Schwarcz (1993) aponta que um dos pontos centrais na representação de uma identidade nacional brasileira é a questão racial. Em um país de mestiços, negros, brancos, indígenas e asiáticos, como se pode encontrar uma identidade nacional? Os tropicalistas, em sua maioria mestiços, eles mesmos jogam com esta questão identitária em suas criações. Utilizo-me, aqui, de uma passagem de Schwarcz que clareia este ponto: "Seja na representação mestiça de finais do século XX, seja na re-elaboração culturalista dos anos 30 , eis que o tema da identidade e da busca de uma singularidade local aparece novamente transvestido nesse país tão afeito à criação de novos mitos de brasilidade." (SCHWARCZ, 1993, p. 250).

Também, nas artes plásticas brasileiras deste período tropicalista, Hélio Oiticica, Lygia Clark e Lygia Pape revolucionam os conceitos de arte da época introduzindo o corpo do espectador co-

\footnotetext{
${ }^{1}$ Assemblage é uma técnica artística que se caracteriza pela acumulação de objetos e materiais, geralmente colados, que formam um conjunto novo e inusitado, porém cheio de sentido. As peças podem ser identificadas individualmente, porém todos os elementos unidos formam um conjunto com força estética própria. A assemblage fornece um ritmo específico de leitura dos materiais agregados. Arthur Bispo do Rosário é um bom exemplo de artista plástico brasileiro que muito se utilizou da técnica da assemblage.
} 
como elemento indispensável em suas obras. Lygia Pape cria em 1968 uma obra chamada "Divisor", onde o espectador dá forma `a obra; Lygia Clark cria seus "Bichos" e Hélio Oiticica cria suas instalações "ambientais", tais como "Tropicália". E é exatamente da instalação "Tropicália", de 1967, de Oiticica, que vem o nome do movimento musical e da canção. Tal instalação traz elementos variados da vida brasileira e que juntos poderiam dar uma sensação artístico-cultural de nosso país. E é essa busca por uma identidade cultural nacional, que tanto os tropicalistas, como Oiticica e outros artistas, tentavam identificar e compreender.

Tal instalação faz referência a vários aspectos da cultura brasileira, porém colocados em um sistema de caos de significação, no qual os elementos dessa "desordem" devem ser rearranjados pelo próprio espectador e com suas próprias referências. O projeto ambiental de Hélio Oiticica diagnostica o problema cultural brasileiro, porém não resolve. A instalação de Oiticica utiliza-se da estratégia de misturar para confundir, de colocar juntos elementos culturais que parecem não se relacionar, mas que fazem contrapontos metafóricos com os elementos marcantes da cultura brasileira. Ele organiza seu discurso estético através de uma miscelânea espetacular de plantas tropicais, pássaros, ambientes, tecidos, pedras, sons, etc., enfim, uma assemblage de coisas aparentemente desiguais e desconexas, mas que têm profunda relação com a cultura brasileira.

Não podemos esquecer que o nome do movimento tropicalista vem da instalação de Hélio Oiticica, mas também, em si mesmo, remete a um ambiente tropical: de praias, palmeiras, muita luz, cores primárias, araras, frutas tropicais (ex: banana, mamão, abacaxi, etc., como nos chapéus de Carmen Miranda), entre outros elementos. Esse jogo com elementos tropicais variados pode parecer uma "brincadeira", porém era um mecanismo de crítico à sociedade brasileira de então. O Movimento Tropicalista se serviu bastante, em suas obras, deste mecanismo de desconstrução do discurso cultural brasileiro da época.

Ainda, a busca por uma identidade cultural nacional subentende a existência de uma "brasilidade" única e a possível identificação desta brasilidade. O que o Movimento Tropicalista faz é jogar com os estereótipos do que seja, de alguma forma, "tipicamente" brasileiro, deixando notório, que não é possível uma clara identificação de tal brasilidade.

Assim, os filmes "Macunaíma" e "Bye Bye Brasil" mostram Brasis diferentes: um estereotipado, divertido e jocoso, e o outro, um Brasil de diferenças, de distâncias e de contrastes. Ambos os filmes se enquadram em uma estética tropicalista pela busca de uma identificação nacional, mesmo que caricata ou inacabada.

Não podemos esquecer a força, na época, da ideia da necessidade de desenvolvimento do país. Nosso subdesenvolvimento parecia incomodar sobremaneira os militares e às classes dominantes. Ambos os filmes trabalham muito bem com esta relação de desenvolvimento versus subdesenvolvimento. Por exemplo, Macunaíma nasce no mato, mas se muda para cidade grande.

O filme "Macunaíma", de Joaquim Pedro de Andrade, de 1969, nos apresenta uma adaptação para o cinema da obra literária homônima, de 1928, de Mário de Andrade (1893-1945), conhecido intelectual modernista brasileiro, um verdadeiro investigador sobre o Brasil. Mário de Andrade influenciou fortemente o movimento tropicalista com sua "mescla" de tudo que era brasileiro: mitos, lendas, representações do urbano e do interior, sobre a nossa "preguiça natural", etc. Mário de Andrade, assim como outros participantes da Semana de Arte de 1922, acontecida em São Paulo, buscaram compreender o Brasil, tentando construir um discurso de brasilidade aplicando elementos de diversas áreas do conhecimento artístico para a compreensão das múltiplas manifestações culturais brasileiras.

Em "Macunaíma" o personagem-título se aproxima de um anti-herói, um herói sem nenhum caráter. Nasce na mata, como um indígena, e se coloca, na visão de Mário de Andrade, como a representação do povo brasileiro. Macunaíma é uma criatura preguiçosa, sua frase-jargão é "Ai, 
que preguiça!". Adora uma rede e busca seu amuleto muiraquitã, que havia recebido de sua falecida esposa, a índia Ci. Torna-se branco e muda-se para a cidade de São Paulo para procurar seu amuleto. Reavê seu talismã e regressa para sua mata.

O filme mostra claramente os mais diversos traços de nossa formação cultural: o indígena, o negro, o branco, o rural, o urbano, o deslumbramento, a preguiça, entre outros. Este filme se enquadra no período inicial do movimento tropicalista, refletindo a busca por uma identificação cultural nacional através da confluência de representações de coisas "tipicamente" brasileiras.

Não podemos esquecer que as obras de Mário de Andrade serviram de inspiração para os tropicalistas, já que este pesquisador buscou, verdadeiramente, compreender o Brasil, viajando pelo país para coletar mitos, lendas, crenças, conhecer personagens interessantes, entre outras expedições. Seus trabalhos apresentam a primeira tentativa de tradução do Brasil, antes mesmo do mito da democracia racial brasileira de Gilberto Freyre, na obra "Casa Grande \& Senzala", de 1933.

Também, o tropicalismo se utilizou de todas as referências possíveis para tentar representar uma determinada brasilidade. Das misturas de raças, da miscigenação, da relação urbano com rural, da oposição desenvolvimento e subdesenvolvimento, do passado e do presente, da herança cultural e do futuro, entre outros pontos. Os tropicalistas foram extremamente originais na utilização destes elementos. Lilia Schwarcz (1993, p. 243) nos dá uma solução para o problema racial brasileiro que pode se relacionar ao que fizeram os tropicalistas: "Contudo, não basta abrir mão do que é emprestado para se chegar ao autêntico, mesmo porque tal renúncia é em si improcedente. O desafio é pensar na originalidade da cópia e na elasticidade desse tipo de doutrina, aplicada em contextos díspares."

Por outro lado, e marcando os fins do tropicalismo, o filme "Bye Bye Brasil" de Carlos (Cacá) Diegues, de 1979, se coloca como um road movie brasileiro. Um grupo mambembe viaja pelo interior do Brasil, parando em cidades pobres e fazendo shows na Caravana Rolidei ${ }^{2}$. Nessas cidades pequenas e humildes do interior do Brasil não existia televisão e a caravana oferecia divertimento, uma vez por ano, a esta população carente. Salomé, Lorde Cigano e Andorinha são os três artistas principais da caravana, mas se juntam a eles o sanfoneiro Ciço e sua esposa grávida Dasdô. O caminho pela rodovia transamazônica até chegar a Altamira é rico em imagens do que é o Brasil do interior nos fins da década de 1970. O filme mostra um movimento desenvolvimentista desbravando a Amazônia. Essas imagens refletiam um Brasil desconhecido no sudeste e no sul do país.

Ao final do filme, Dasdô e Ciço decidem se fixar em Brasília. São levados pelo serviço social a um subúrbio pobre da capital federal, onde sobrevivem fazendo shows para seus conterrâneos nordestinos (os candangos) que se deslocaram para construir a capital federal. Ele tocando seu acordeon e ela tocando um triângulo. Lorde Cigano e Salomé vêm buscá-los com o novo caminhão da Caravana Rolidei, mas Dasdô e Ciço decidem não partir.

Também, a imagem de Brasília representa o urbano, o novo Brasil, o desenvolvimento, enquanto os próprios candangos que a vieram construir, gente pobre e trabalhadora, representam o subdesenvolvimento. Esse tipo de relação é deixada muito clara na estética tropicalista.

Ainda, a ida e a fixação de Ciço e sua esposa Dasdô no subúrbio de Brasília se relaciona com a construção da capital "no planalto central do país", como se pode notar na música "Tropicália"

\footnotetext{
${ }^{2}$ Abrasileiramento da palavra em língua inglesa "holiday", que nos EUA significa feriado (religioso ou não) e no Reino Unido significa férias do trabalho ou estudo. Ou seja, um período fora do tempo de trabalho, um tempo para divertirse, um período de ócio.
} 
de Caetano Veloso. Também as imagens contrastantes de desenvolvimento e subdesenvolvimento podem se relacionar com a música de Caetano.

Pode-se dizer, também, que fazer um road movie pela rodovia transamazônica não era só inusitado, mas audacioso. Cacá Diegues desejava mostrar um Brasil que a maior parte da população das grandes cidades não conhecia, e ainda hoje não conhece. A rodovia transamazônica representava o novo Brasil, uma nova fronteira de desenvolvimento aberta no norte do país. A ideia de progresso foi predominante na década de 1970, principalmente na mentalidade dos militares.

Podemos, também, relacionar estes dois audaciosos filmes à época histórica em que foram pensados e executados: durante a ditadura militar. A audácia de interpretar culturalmente o Brasil e tentar buscar uma identidade cultural nacional foi brilhante. Podemos claramente afirmar que estes dois filmes marcaram o começo e fim do Tropicalismo.

Além disto, a força representativa das imagens em movimento do cinema utilizadas para retratar uma variedade imensa de brasis desconhecidos e desconexos no imaginário das pessoas, mostra quão importante para a cultura brasileira foram os trabalhos cinematográficos na formação de uma identidade cultural nacional. A importância de ver estes brasis desconhecidos e contrastantes exigia do espectador uma tomada de posição, uma atitude crítica perante o que era visto e experienciado.

A força do cinema enquanto formador de opinião no século $X X$ foi incontestável. $O$ próprio movimento tropicalista foi grandemente influenciado pelos filmes do Cinema Novo, principalmente pelo filme "Deus e o diabo na terra do sol", de 1964, de Glauber Rocha. O movimento do Cinema Novo tinha uma estética de repúdio à retorica intelectualizada, buscava uma linguagem simples, tentava mostrar o povo ao povo e suas ideias eram claras e diretas. Essa estética do Cinema Novo também era usada pelo Tropicalismo, mas com o auxílio das metáforas, das polarizações, das misturas, das bricolagens, das alternâncias, das revisões e das evidências, para não ter os trabalhos tropicalistas censurados pela ditadura militar.

Se o filme "Macunaíma" busca o jogo irônico de raças e paisagens, "Bye Bye Brasil" destaca que a intenção modernista de Mário de Andrade ainda era necessária e podia ser utilizada enquanto mecanismo discursivo e criativo. Utilizo-me, aqui, de uma passagem de Ana Mae Barbosa (1995, p. 61) sobre a atualidade do mecanismo Antropofágico Modernista (neste caso, de Oswald de Andrade) para a análise cultural no pós-colonialismo:

Na verdade, importamos nossos próprios valores distorcidos pelo colonizador. Entretanto,
no Brasil, a voz precursora de Oswald de Andrade conclamava pela atitude, defendida
depois pelos pós-colonialistas como Albert Memmi e Paulo Freire, de lutar por um lugar
na história, embora feita na Europa, designado, nominado pelo próprio colonizado. O cu-
bano Roberto Retamar, na década de 70, atualizou o conceito de antropofagia de Oswald
de Andrade, canibalizando-o e tornando-o pós-colonial na teoria e contra discursivo na
prática. Como profetizou Oswald de Andrade, hoje podemos definir o pós-colonialismo
cultural no Brasil como antropofágico e canibalesco. Deglute, desconstrói e reorganiza
as influências da Europa e dos Estados Unidos. Nem mais a dependência cultural, nem
mais a busca inalcançável da originalidade modernista, mas adequação e elaboração em
diálogo com os países centrais.

Podemos dizer, então, que o movimento tropicalista foi um "novo movimento antropofágico", porém mais atual que aquele dos modernistas e que tentava, através da jocosidade crítica, refletir sobre uma nação de identidade cultural brasileira que não se firma completamente, buscando levantar posições críticas às várias referências culturais que usualmente "nos representam". 


\title{
3 | CONSIDERAÇÕES FINAIS
}

Para terminar este texto, utilizo-me de uma bela passagem de Lilia Scwarcz (1993, p. 247), no qual nos deixa ver uma pequena historiografia de como se lidou com a questão racial no Brasil, ponto crucial de nossa complexidade cultural:

\begin{abstract}
De fato, a interpretação racial, a constatação de que essa era uma nação singular porque miscigenada, é antiga e estabelecida no país. Tema de ensaio vitorioso do naturalista Von Martius para o IHGB em inícios do século passado, retomada principalmente por Silvio Romero nos anos 80 , para surgir reelaborada em inícios do século atual com Gilberto Freyre, eis que a interpretação persiste mesmo em momentos e modelos teóricos diversos. Da constatação da hibridização em Von Martius à afirmação darwinista em Romero, para se chegar ao elogia à democracia racial com Gilberto Freire, percebe-se como é arraigado $o$ argumento de que $\mathrm{o}$ 'Brasil se define pela raça'.
\end{abstract}

No entanto, apesar das palavras de Lilia Scwarcz, meu argumento é de que o Brasil se define por suas criações culturais em todas as áreas: seja nas artes, nos costumes, nas comidas, nas brincadeiras, etc. E os filmes mencionados, com clara influência da estética tropicalista, transparecem nitidamente que a multiplicidade e a heterogeneidade não é negativa, mas nos dá possibilidades criativas inusitadas, sejam elas no campo econômico, político, social, legal e cultural. Nossa miscigenação deve ser uma verdadeira mescla de tudo que somos e nos representa e que, ainda, nos deixa ser quem somos enquanto indivíduos.

Os filmes apresentados marcam claramente este ponto na história cultural brasileira na qual a miscigenação, a mescla, a relação de coisas aparentemente diferentes, pode resultar em algo rico e original, diferentemente do domínio legal que vivemos em nossa época atual de fortalecimento de cidadania e de reconhecimento legal. Não que os anseios atuais não sejam válidos, mas diferem claramente da originalidade e criatividade baseadas na miscigenação.

A interpretação e representação do nosso mundo através do cinema nos serve, enquanto brasileiros, para o fortalecimento dos processos de identidade e cidadania, garantindo um senso reflexivo e crítico sobre o que somos, como somos, quem somos, quem queremos ser e como o faremos para sê-lo.

Nossas várias identidades culturais nacionais parecem se caracterizar por uma elasticidade estética e pela aceitação do diferente. Afinal, em um país de dimensões continentais não dá para ser igual de norte a sul. É neste sentido, que os mecanismos estéticos tropicalistas, de inventariar os elementos culturais aparentemente "dispares" e chocá-los, somente nos levam a pensar nas diferenças enquanto riqueza cultural a ser preservada e repassada. 


\section{Referências}

BARBOSA, Ana Mae. Arte-educação pós-colonialista no Brasil: aprendizagem triangular. Comunicação e Educação, São Paulo, n. 2, p. 59-64, jan./abr. 1995.

BHABHA, Homi K. Postmodernism /postcolonialism. In: NELSON, Robert S; SHIFF, Richard (Ed.). Critical terms for art history. 2. ed. Chicago: The University of Chicago Press, 2003. p. 435-451.

FAVARETTO, Celso. Tropicália e antropofagia. In: Tropicália: alegoria, alegria. São Paulo:

Kairós, 1979. p. 34-53.

GEERTZ, Clifford. A interpretação das culturas. Rio de Janeiro: LTC, 2008.
JOHNSON, Randal. Brazilian narrative. In: KING, John (Ed.). The Cambridge companion to modern latin American culture. Cambridge: Cambridge University Press, 2004. p. 119-135.

SCHWARCZ, Lilia Moritz. Entre o veneno e o antídoto: algumas considerações finais. In: O espetáculo das raças: cientistas, instituições e questão racial no Brasil - 1870-1930. São Paulo: Companhia das Letras, 1993. p. 239-250.

WISNIK, José Miguel. O minuto e o milênio ou por favor, professor, uma década de cada vez. In: BAHIANA, Ana Maria; WISNIK, José Miguel; AUTRAN, Margarida. Anos 70. Rio de Janeiro: Europa Editora, 1979. p. 7-23. 